\title{
Inhibition of Mild Steel Corrosion Using L-tryptophan and Synergistic Surfactant Additives
}

\author{
M. Mobin, Mosarrat Parveen, M. Alam Khan \\ Corrosion Research Laboratory, Department of Applied Chemistry, Faculty of Engineering \& \\ Technology, Aligarh Muslim University, Aligarh, India-202 002 (India)
}

Received 11 March 2011; accepted 12 November 2011

\begin{abstract}
The corrosion inhibition characteristics of nitrogen containing amino acid L-tryptophan on mild steel in $0.1 \mathrm{M} \mathrm{HCl}$ solution, in the temperature range of $30-50{ }^{\circ} \mathrm{C}$, was studied by weight loss and potentiodynamic polarization measurements. L-tryptophan significantly reduces the corrosion rates of mild steel; the maximum inhibition efficiency being $83 \%$ at $50{ }^{\circ} \mathrm{C}$ in presence of inhibitor concentration of $500 \mathrm{ppm}$. The effect of the addition of very small concentrations of anionic surfactant, sodium dodecyl sulfate (SDS), and of cationic surfactant, cetyl trimethyl ammonium bromide (CTAB), on the corrosion inhibition behavior of L-tryptophan was also studied. The inhibition efficiency (IE) of L-tryptophan significantly improved in presence of both surfactants. The effect of SDS and CTAB on the corrosion inhibition behavior of L-tryptophan appears to be synergistic in nature, the values of synergism parameter being greater than unity. The adsorption of inhibitors on mild steel surface obeyed Langmuir's adsorption isotherm. The calculated thermodynamic parameters for adsorption reveal a strong interaction between the inhibitors and the mild steel surface. The results obtained by electrochemical studies are consistent with the results of the weight loss measurements. L-tryptophan acts more anodic than cathodic inhibitor.
\end{abstract}

Keywords: L-tryptophan, corrosion inhibitor, adsorption, surfactants, electrochemical technique.

\section{Introduction}

Among the several methods to save the metals from corrosion, the use of inhibitors has found wide attention both in academia and industries. The corrosion inhibitors are generally used to protect metals against the attack of the acid solutions, which are widely used in acid pickling, industrial cleaning, acid descaling, oil-well acidizing, etc. Organic compounds containing nitrogen, sulfur

\footnotetext{
* Corresponding author. E-mail address: drmmobin@ @otmail.com
} 
and oxygen have been widely used as potential corrosion inhibitors in acid solutions [1-3]. These compounds prevent corrosion either by getting adsorbed, or by forming a protective layer or an insoluble complex on the metal surface, thus blocking the active corrosion sites. However, most of the organic compounds are synthetic chemicals, expensive and very hazardous to both human beings and the environments, and need to be replaced by non toxic and environmental friendly compounds.

In recent years, a number of eco-friendly compounds such as extract of common plants which contain many organic compounds, e.g., alkaloids, fatty acids, carbohydrates, tannins, pigments and amino acids, have been exploited as green alternative to toxic and hazardous compounds [4]. The amino acids which contain carboxyl and amino functionalities bonded to the same carbon atom are non-toxic, relatively cheap and easy to produce in purities greater than $99 \%$. It has been shown by various authors that some amino acids can act as corrosion inhibitors, which has generated an increasing interest in these compounds as substitutes to conventional corrosion inhibitors that are usually toxic [5-9]. The inhibition effect of three amino acids, namely, alanine, glycine and leucine, against steel corrosion in $\mathrm{HCl}$ solutions has been investigated by potentiodynamic polarization method. The inhibition effect was found to range from 28-91\% [10]. The corrosion inhibition of $\mathrm{Fe}$ in $1 \mathrm{M} \mathrm{HCl}$ using twenty two different common amino acids and four related compounds has been investigated using potentiodynamic polarization curves [11]. In general, amino acids with longer hydrocarbon chains showed greater inhibition. Additional groups or groups which increased electron density on alpha amino group also increased the inhibition efficiency.

The nitrogen containing amino acid L-tryptophan is a derivative of indole. The molecular structure of the compound suggests that it has strong potential to become an effective corrosion inhibitor. Moretti and Guidi [12] reported the corrosion inhibition of L-tryptophan on copper in aerated $0.5 \mathrm{M} \mathrm{H}_{2} \mathrm{SO}_{4}$ in the temperature range of $20-50{ }^{\circ} \mathrm{C}$. The corrosion rate did not rise as temperature increased. Recently, corrosion inhibition behavior of low carbon steel by Ltryptophan was investigated using weight loss experiments and Tafel polarization curves [13]. The adsorption behavior of L-tryptophan at Fe surface was also investigated by the molecule dynamics simulation method and density functional theory. The results indicated that L-tryptophan could adsorb on Fe surface through the indole ring with $\pi$-electrons and nitrogen/oxygen atom with the lone pair electrons in its molecule.

The majority of the acidic inhibitors have been known for their specificity of inhibition action. A combination of inhibitors is likely to provide multiple effects required for effective corrosion inhibition. The addition of halide ions to organic compounds has shown synergistic effect and resulted in improved inhibition efficiency of many organic compounds, and has been reported in the literature [14]. However, the influence of surfactants on the corrosion inhibition behavior of organic compounds is very scanty [15].

Surfactants have effectively been used as corrosion inhibitors as their molecules possess strong adsorption ability to the metallic surfaces. The adsorbed 
molecules form monolayer or bilayer hemimicelles or admicelles, depending upon the surfactant concentration, and prevent the acid to attack the surface, and thus reduce the corrosion attack [16-19]. Amino acids interact with the surfactants to form a complex structure and help to adhere to surface, which offers great promise in corrosion inhibition. The binding of surfactants to amino acids depends upon the structure, molecular weights, interaction times and charge densities. A survey of literature indicates that only limited number of references is available dealing with the corrosion inhibition effect of Ltryptophan on mild steel. Further, the corrosion inhibition effect of amino acids in presence of surfactants has not yet been reported to the best of our knowledge. However, the influence of some surfactants on the corrosion inhibition of some oxidiazoles has recently been reported [15]. The adsorption of oxidiazoles on mild steel surface is reported to be significantly enhanced in presence of surfactants.

The present work was undertaken to investigate the corrosion inhibition behavior of L-tryptophan on mild steel in $0.1 \mathrm{M} \mathrm{HCl}$ solution. The effect of the addition of very small concentrations of SDS and CTAB on the corrosion inhibition behavior of L-tryptophan, for which no reference is available in the literature, was also studied. The techniques used are weight loss and potentiodynamic polarization measurements.

\section{Experimental}

\section{Material preparation}

Mild steel specimens having composition (weight \%): $0.20 \% \mathrm{C}, 0.53 \% \mathrm{Mn}$, $0.11 \% \mathrm{~S}, 0.036 \% \mathrm{Si}$ and $0.098 \% \mathrm{P}$, and balance $\mathrm{Fe}$, were used for corrosion inhibition studies. The inhibitor L-tryptophan [(2S)-2-amino-3-(1-H-indol-3-yl) propanoic acid; molecular mass $204.23 \mathrm{~g} \mathrm{~mole}^{-1}$ ], anionic surfactant, sodium dodecyl sulfate (SDS), cationic surfactant, N-cetyl N,N,N-trimethyl ammonium bromide (CTAB) (CDH, India), were used as received. The other chemicals used were all reagent grade. The stock solution of $\mathrm{HCl}$ and inhibitors were prepared using double distilled water.

\section{Weight loss measurements}

Mild steel coupons of dimension $2.5 \times 2.0 \times 0.03 \mathrm{~cm}$ were used for weight loss measurements. The coupons were machined and abraded on different grit $\mathrm{SiC}$ papers and finally washed and degreased using acetone, and dried up. To hold the specimens a hole of $1.5 \mathrm{~mm}$ dia was made near the edge. The weight loss studies were carried out in the temperature range of $30-50{ }^{\circ} \mathrm{C}$ in $0.1 \mathrm{M} \mathrm{HCl}$. The test solution was made of $\mathrm{AR}$ grade $35 \% \mathrm{HCl}$ using double distilled water. The concentration of L-tryptophan was kept between 1 to $500 \mathrm{ppm}$ in $\mathrm{HCl}$. The weight loss experiments were performed for duration of $6 \mathrm{~h}$, as per ASTM designation G1-90. The inhibition efficiency (\% IE) was calculated by using the following equation: 


$$
\% I E=\frac{C R_{o}-C R_{i}}{C R_{o}} \times 100
$$

where, $\mathrm{CR}_{\mathrm{o}}=$ corrosion rate of mild steel in blank $\mathrm{HCl} ; \mathrm{CR}_{\mathrm{i}}=$ corrosion rate of mild steel in presence of the inhibitor.

\section{Potentiodynamic polarization measurements}

The potentiodynamic polarization measurements were carried out using an EG and $\mathrm{G}$ potentiostat/galvanostat, model 263A. The experiments were carried out using a corrosion cell from $\mathrm{EG}$ and $\mathrm{G}$; model $\mathrm{K} 0047$ with $\mathrm{Ag} / \mathrm{AgCl}$ electrode (saturated $\mathrm{KCl}$ ) as reference electrode, Pt wire as counter electrode and steel coupons as working electrode. The experiments were performed using a scan rate of $0.166 \mathrm{mV} / \mathrm{S}$, commencing at a potential above $250 \mathrm{mV}$ more active than the stable open circuit potential. All the measurements were carried out at room temperature $\left(30 \pm 1{ }^{\circ} \mathrm{C}\right)$. Before starting the measurements the specimen was left to attain a steady state indicated by a constant potential. The inhibition efficiency was calculated using the relationship:

$$
I E(\%)=\left(1-\frac{i_{c o r r}}{i_{c o r r}^{o}}\right) \times 100
$$

where $i_{\text {corr }}=$ inhibited current density and $i_{\text {corr }}^{\mathrm{o}}=$ uninhibited current density.

Table 1. Corrosion parameters for mild steel in $0.1 \mathrm{M} \mathrm{HCl}$ in absence and presence of L-tryptophan at $30-50{ }^{\circ} \mathrm{C}$ from weight loss measurements.

\begin{tabular}{ccccccc}
\hline & \multicolumn{3}{c}{ Corrosion rate (mpy) } & \multicolumn{3}{c}{ Inhibition efficiency (\% I) } \\
L-tryptophan Conc. (ppm) & $30{ }^{\circ} \mathrm{C}$ & $40{ }^{\circ} \mathrm{C}$ & $50{ }^{\circ} \mathrm{C}$ & $30{ }^{\circ} \mathrm{C}$ & $40{ }^{\circ} \mathrm{C}$ & $50{ }^{\circ} \mathrm{C}$ \\
\hline Blank & 102.14 & 253.62 & 874.47 & - & - & - \\
10 & 57.42 & 131.32 & 551.57 & 44.29 & 47.98 & 36.15 \\
50 & 55.03 & 101.46 & 348.80 & 46.43 & 60.12 & 60.14 \\
100 & 47.68 & 80.25 & 207.21 & 53.57 & 68.21 & 76.18 \\
200 & 46.93 & 78.79 & 200.94 & 54.29 & 68.79 & 76.86 \\
400 & 42.53 & 88.46 & 154.01 & 58.57 & 65.32 & 82.26 \\
500 & 36.67 & 75.52 & 146.67 & 64.29 & 70.23 & 83.11 \\
\hline
\end{tabular}

\section{Results and discussion}

\section{Weight loss measurements}

The corrosion of mild steel in $0.1 \mathrm{M} \mathrm{HCl}$ in absence and presence of different concentrations of amino acid L-tryptophan was studied in the temperature range of $30-50{ }^{\circ} \mathrm{C}$ using weight loss technique. Table 1 shows the calculated values of weight loss, corrosion rate and IE at different concentrations of L-tryptophan 
under different temperatures. From these data it is clearly seen that the corrosion rate of mild steel depends upon two factors, namely inhibitor concentration and temperature. The corrosion rates are significantly reduced in presence of Ltryptophan. The maximum increase in IE of $64 \%$ was observed at a concentration of $500 \mathrm{ppm}$ at $30{ }^{\circ} \mathrm{C}$, which further increased to $83 \%$ on increasing the temperature from 30 to $50{ }^{\circ} \mathrm{C}$. The plots of IE as a function of L-tryptophan concentration, at $30-50{ }^{\circ} \mathrm{C}$, reveal that IE increases with increase in concentration (Fig. 1a).

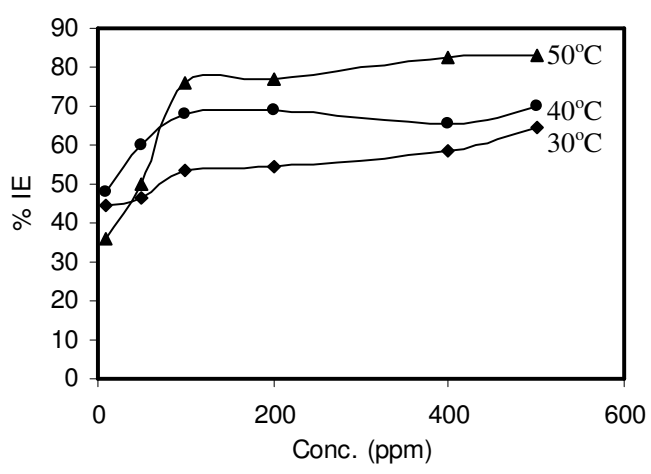

a)

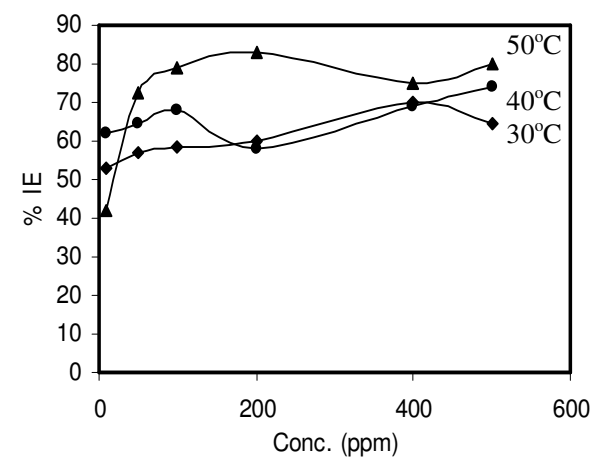

b)

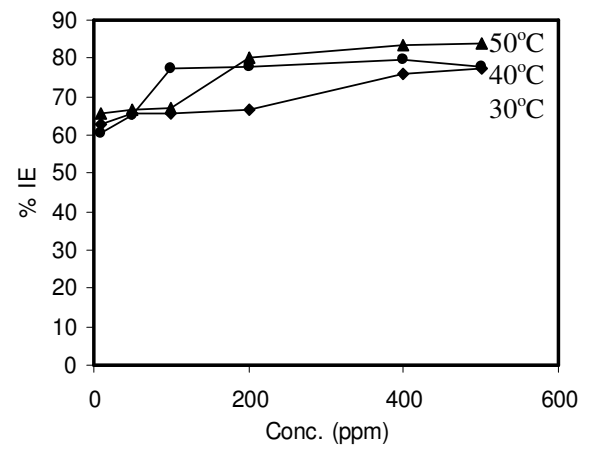

c)

Figure 1. Plots of inhibition efficiency (IE) vs. inhibitor concentration for mild steel in $0.1 \mathrm{M} \mathrm{HCl}$ at different temperatures: (a) L-tryptophan; (b) L-tryptophan + SDS; (c) Ltryptophan + CTAB. 
Table 2. Calculated values of corrosion rate, inhibition efficiency and synergism parameter for mild steel in $0.1 \mathrm{M} \mathrm{HCl}$ in the absence and presence of different concentrations of L-tryptophan with SDS at 30-50 ${ }^{\circ} \mathrm{C}$, from weight loss measurements.

\begin{tabular}{cccccccccccc}
\hline \multicolumn{1}{c}{ Inhibitor conc. (ppm) } & \multicolumn{1}{c}{ Corrosion rate (mpy) } & \multicolumn{2}{c}{ Inhibition efficiency (\% I) } & \multicolumn{5}{c}{ Synergism parameters $\left(\mathrm{S}_{1}\right)$} \\
L-tryptophan & SDS & $30{ }^{\circ} \mathrm{C}$ & $40{ }^{\circ} \mathrm{C}$ & $50{ }^{\circ} \mathrm{C}$ & $30{ }^{\circ} \mathrm{C}$ & $40{ }^{\circ} \mathrm{C}$ & $50{ }^{\circ} \mathrm{C}$ & $30{ }^{\circ} \mathrm{C}$ & $40{ }^{\circ} \mathrm{C}$ & $50{ }^{\circ} \mathrm{C}$ \\
\hline Blank & Blank & 102.39 & 253.62 & 874.47 & - & - & - & - & - & - \\
- & 1 & 87.55 & 196.51 & 538.43 & 14.29 & 24.85 & 37.67 & - & - & - \\
10 & 1 & 48.62 & 97.69 & 503.57 & 52.86 & 61.85 & 42.23 & 1.11 & 1.18 & 1.77 \\
50 & 1 & 44.00 & 89.82 & 237.61 & 57.14 & 64.74 & 72.63 & 1.06 & 1.31 & 1.21 \\
100 & 1 & 42.53 & 80.67 & 183.87 & 58.57 & 68.21 & 79.22 & 1.16 & 1.36 & 1.44 \\
200 & 1 & 41.07 & 88.46 & 146.67 & 60.00 & 65.32 & 83.11 & 1.14 & 1.44 & 1.38 \\
400 & 1 & 30.80 & 79.20 & 217.08 & 70.00 & 68.79 & 75.00 & 1.04 & 1.31 & 1.61 \\
500 & 1 & 36.67 & 66.00 & 173.07 & 64.28 & 73.99 & 80.07 & 1.22 & 1.28 & 1.51 \\
\hline
\end{tabular}

Table 3. Calculated values of corrosion rate, inhibition efficiency and synergism parameter for mild steel in $0.1 \mathrm{M} \mathrm{HCl}$ in the absence and presence of different concentrations of L-tryptophan with $\mathrm{CTAB}$ at $30-50{ }^{\circ} \mathrm{C}$, from weight loss measurements.

\begin{tabular}{cccccccccccc}
\hline \multicolumn{2}{c}{ Inhibitor conc. (ppm) } & \multicolumn{3}{c}{ Corrosion rate (mpy) } & \multicolumn{3}{c}{$\begin{array}{c}\text { Inhibition efficiency } \\
(\% \mathrm{I})\end{array}$} & \multicolumn{3}{c}{ Synergism parameters } \\
\hline L-tryptophan & $\mathrm{CTAB}$ & $30{ }^{\circ} \mathrm{C}$ & $40{ }^{\circ} \mathrm{C}$ & $50{ }^{\circ} \mathrm{C}$ & $30{ }^{\circ} \mathrm{C}$ & $40{ }^{\circ} \mathrm{C}$ & $50{ }^{\circ} \mathrm{C}$ & $30{ }^{\circ} \mathrm{C}$ & $40{ }^{\circ} \mathrm{C}$ & $50{ }^{\circ} \mathrm{C}$ \\
\hline Blank & Blank & 102.14 & 253.62 & 874.47 & - & - & - & - & - & - \\
- & 1 & 53.01 & 99.22 & 249.34 & 48.57 & 60.69 & 71.28 & - & - & - \\
10 & 1 & 38.13 & 99.22 & 304.97 & 62.86 & 60.69 & 65.67 & 1.48 & 1.51 & 2.09 \\
50 & 1 & 35.57 & 90.34 & 291.83 & 65.71 & 65.32 & 66.39 & 1.45 & 1.86 & 2.53 \\
100 & 1 & 35.57 & 56.91 & 285.99 & 65.71 & 77.46 & 66.89 & 1.56 & 1.67 & 2.22 \\
200 & 1 & 34.83 & 56.03 & 177.68 & 66.43 & 78.03 & 80.07 & 1.55 & 1.66 & 1.86 \\
400 & 1 & 24.93 & 51.60 & 146.05 & 75.71 & 79.77 & 83.61 & 1.42 & 1.58 & 1.84 \\
500 & 1 & 23.47 & 55.45 & 143.04 & 77.14 & 78.03 & 83.95 & 1.46 & 1.68 & 1.84 \\
\hline
\end{tabular}

Except at very low concentration of L-tryptophan (up to $10 \mathrm{ppm}$ ), IE increases with increasing temperature. The inhibition behavior of L-tryptophan on mild steel in $0.1 \mathrm{M} \mathrm{HCl}$ can be attributed to the adsorption of the molecules on the steel surface. The effectiveness of the adsorption of L-tryptophan may be attributed to the presence of two nitrogen atoms in the molecule and its large volume [20]. The increased IE with increasing the inhibitor concentration indicates that more inhibitor molecules are adsorbed on the steel surface, leading 
to the formation of a protective film [21]. The increase in IE with increasing temperature suggests that at higher concentrations L-tryptophan is chemically adsorbed on to the mild steel surface. At lower concentrations the adsorbed film is not so stable and gets damaged at higher temperature, thus showing lower IE. The amino acid, L-tryptophan is easily protonated and expected to involve two ways of adsorption. Firstly, it may be adsorbed via donor-acceptor interactions between the $\pi$ electrons of the indole rings and the unshared electron pairs of the heteroatom, to form a bond with vacant d-orbital of the metal surface [22]. Secondly, the $-\mathrm{NH}_{2}$ group of amino acid in acid medium is readily protonated and might get adsorbed on the metallic surface via the negatively charged acid anions [23].

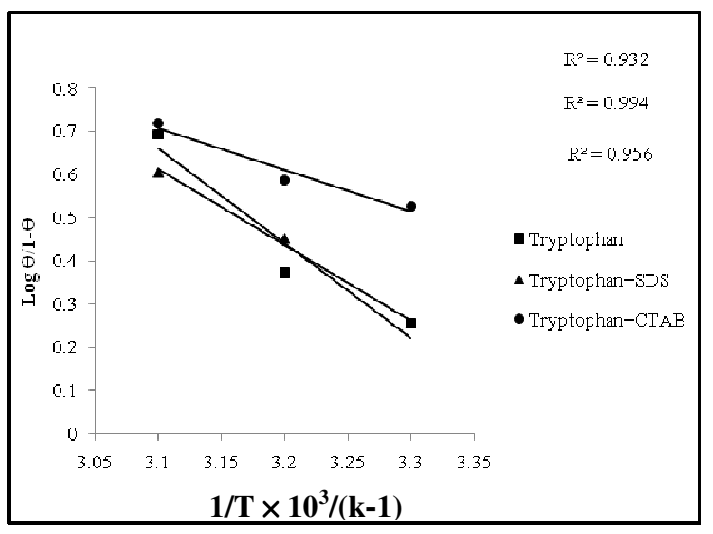

Figure 2. Arrhenius plot for $\log \theta / 1-\theta$ vs. 1/T ( L-tryptophan; $\boldsymbol{\Delta}$ L-tryptophan + SDS; - L-tryptophan + CTAB).

To observe the effect of SDS and CTAB on the corrosion inhibition behavior of L-tryptophan, the corrosion of mild steel in $0.1 \mathrm{M} \mathrm{HCl}$ in absence and presence of different concentrations of L-tryptophan, in combination with $1 \mathrm{ppm}$ of SDS and $1 \mathrm{ppm}$ of CTAB, was separately studied in the temperature range of $30-50{ }^{\circ} \mathrm{C}$ by weight loss technique. The results are shown in Tables 2 and 3 . The corrosion rates of mild steel in $0.1 \mathrm{M} \mathrm{HCl}$ in presence of L-tryptophan in combination with surfactants is further reduced in comparison to L-tryptophan alone. Fig. 1b and 1c show the plots of IE as a function of concentration of L-tryptophan in combination with $1 \mathrm{ppm}$ of SDS and CTAB, respectively, at $30-50{ }^{\circ} \mathrm{C}$.

Table 4. Thermodynamic parameters for corrosion of mild steel in absence and presence of L-tryptophan and surfactants.

\begin{tabular}{ccccc}
\hline $\begin{array}{c}\text { L-tryptophan conc. } \\
(\mathrm{ppm})\end{array}$ & $\begin{array}{c}\text { Surfactant conc. } \\
(\mathrm{ppm})\end{array}$ & $\Delta \mathrm{H}\left(\mathrm{kjmol}^{-1}\right)$ & $-\Delta \mathrm{S}\left(\mathrm{jk}^{-1} \mathrm{~mol}^{-1}\right)$ & $-\mathrm{Q}\left(\mathrm{kjmol}^{-1}\right)$ \\
\hline Blank & - & 86.54 & 78.49 & - \\
500 & 0.0 & 54.95 & 33.76 & 41.8 \\
500 & $1(\mathrm{SDS})$ & 61.81 & 11.62 & 33.51 \\
500 & $1(\mathrm{CTAB})$ & 72.47 & 20.09 & 18.19 \\
\hline
\end{tabular}


Considering the effect of surfactants on the corrosion inhibition behavior of Ltryptophan, the anionic SDS binds with L-tryptophan through electrostatic interaction, thus helps to adsorb at the metal surface more firmly and displays higher IE. The IE of L-tryptophan in presence of $1 \mathrm{ppm}$ of CTAB is also higher, but lower in comparison to SDS.

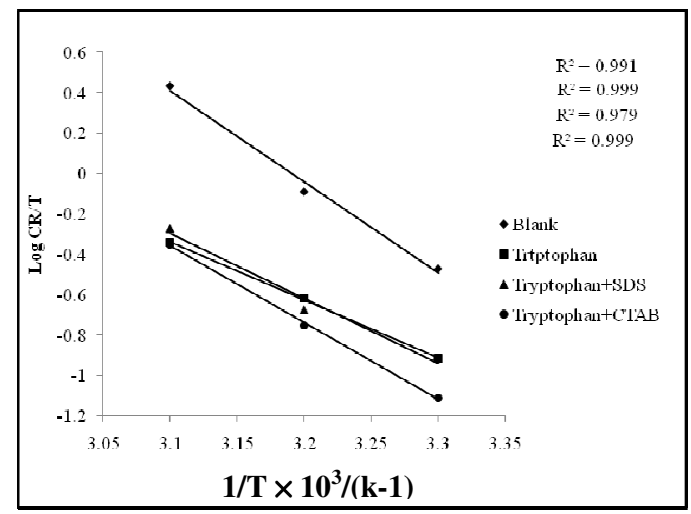

Figure 3. Arrhenius plot for $\log \mathrm{CR} / \mathrm{T}$ vs. 1/T $($ Blank; L-tryptophan; $\boldsymbol{\Delta} \mathrm{L}-$ tryptophan + SDS; $\bullet$ L-tryptophan + CTAB).

It may be due to the adsorption of L-tryptophan to metal surface by binding with CTAB as co-ions or through hydrophobic interaction. The effect of surfactants on the IE of L-tryptophan in $0.1 \mathrm{M} \mathrm{HCl}$ appears to be synergistic in nature. The values of the synergism parameter $S_{1}$ for various concentrations of L-tryptophan in combination with 1 ppm of surfactants were calculated from the gravimetric data at $30{ }^{\circ} \mathrm{C}$ using the relationship [14]

$$
\mathrm{S}_{1}=\frac{1-\mathrm{I}_{1+2}}{1-\mathrm{I}_{1+2}^{\prime}}
$$

where, $\mathrm{I}_{1+2}=\left(\mathrm{I}_{1}+\mathrm{I}_{2}\right)$; $\mathrm{I}_{1}$ is IE of L-tryptophan; $\mathrm{I}_{2}$ is IE of the surfactants; and $\mathrm{I}_{1}^{\prime}$ +2 being IE of L-tryptophan is in combination with surfactants. The results are given in Tables 2 and 3. The values are all greater than unity. This is an indication that the enhanced IE resulting from the addition of surfactants to Ltryptophan is synergistic in nature and proved that addition of a very small concentration of surfactants can improve the adsorption of L-tryptophan on the mild steel.

The inhibition of mild steel corrosion in presence of various organic compounds has been attributed to their adsorption on the steel surface, being generally confirmed from the fit of the experimental data to various adsorption isotherms. The degree of surface coverage $(\theta)$ for various concentrations of L-tryptophan, and L-tryptophan in combination with $1 \mathrm{ppm}$ of SDS and CTAB, in $0.1 \mathrm{M} \mathrm{HCl}$ at $30-50{ }^{\circ} \mathrm{C}$, for $6 \mathrm{~h}$ immersion time, has been evaluated by weight loss measurements. The data were tested graphically by fitting to various isotherms and the best result was obtained for Langmuir adsorption isotherm. 
Table 5. Thermodynamic parameters for mild steel in $0.1 \mathrm{M} \mathrm{HCl}$ in presence of Ltryptophan and surfactants.

\begin{tabular}{lccc}
\hline \multirow{2}{*}{ Inhibitor conc. $\left(\mathrm{mol} \mathrm{dm}^{-3}\right)$} & \multicolumn{3}{c}{$-\Delta \mathrm{G}^{\mathrm{o}}$ ads } \\
\cline { 2 - 4 } & $303 \mathrm{~K}$ & $313 \mathrm{~K}$ & $323 \mathrm{~K}$ \\
\hline L-tryptophan 0.10 & 29.69 & 32.28 & 34.38 \\
L-tryptophan 0.20 & 28.01 & 30.55 & 32.61 \\
L-tryptophan 0.40 & 26.70 & 28.33 & 31.66 \\
L-tryptophan 0.50 & 26.74 & 28.33 & 31.21 \\
SDS + L-tryptophan & & & \\
$0.001+0.10$ & 30.20 & 32.28 & 34.85 \\
$0.001+0.20$ & 28.59 & 29.31 & 33.67 \\
$0.001+0.40$ & 27.96 & 28.74 & 30.48 \\
$0.001+0.50$ & 26.75 & 28.81 & 30.67 \\
CTAB + L-tryptophan & & & \\
$0.001+0.10$ & 30.96 & 33.49 & 33.15 \\
$0.001+0.20$ & 29.29 & 31.78 & 33.14 \\
$0.001+0.40$ & 28.69 & 30.25 & 31.90 \\
$0.001+0.50$ & 28.32 & 29.39 & 31.37 \\
\hline
\end{tabular}

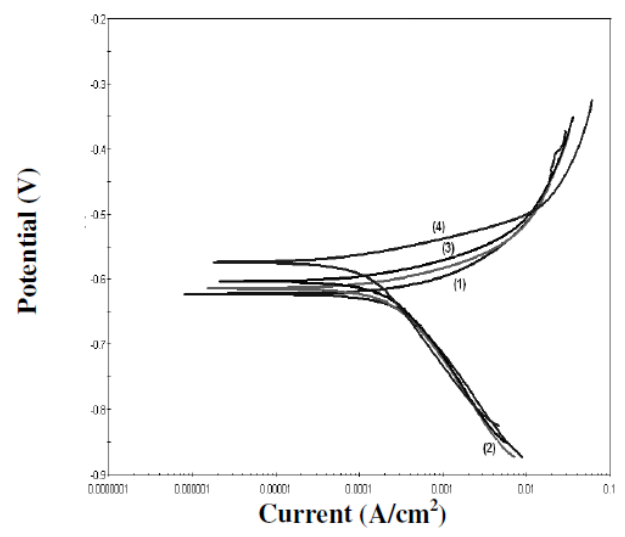

Figure 4. Potentiodynamic polarization curves of mild steel in $0.1 \mathrm{M} \mathrm{HCl}$ in absence and presence of different concentrations of L tryptophan: (1) Blank; (2) $100 \mathrm{ppm}$; (3) 200 ppm; (4) 500 ppm.

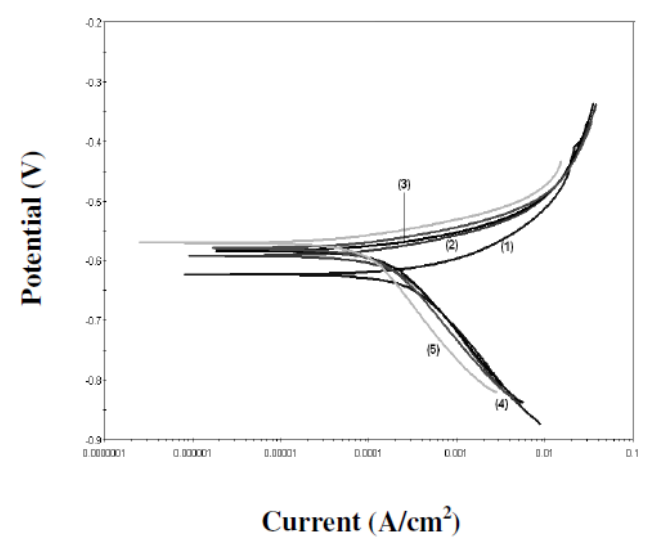

Figure 5. Potentiodynamic polarization curves for mild steel in $0.1 \mathrm{M} \mathrm{HCl}$ in absence and presence of L-tryptophan and SDS: (1) Blank; (2) L-tryp 100 ppm + SDS 1 ppm; (3) L-tryp 200 ppm + SDS 1 ppm; (4) L-tryp 400 ppm + SDS 1 ppm; (5) L-tryp 500 ppm. + SDS 1 ppm. 


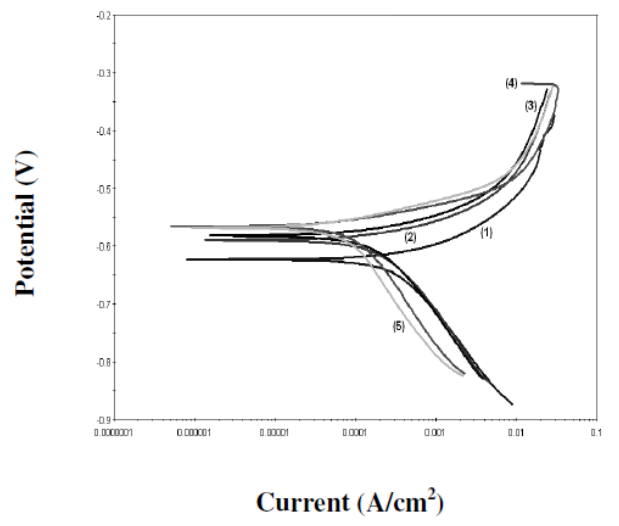

Figure 6. Potentiodynamic polarization curves for mild steel in $0.1 \mathrm{M} \mathrm{HCl}$ in absence and presence of L-tryptophan and CTAB: (1) Blank; (2) L-tryp 100 ppm + CTAB 1 ppm; (3) L-tryp 200 ppm + CTAB 1 ppm; (4) L-tryp 400 ppm+ CTAB 1 ppm; (5) Ltryp 500 ppm+ CTAB 1 ppm.

Table 6. Potentiodynamic polarization parameters for corrosion of mild steel in $0.1 \mathrm{M}$ $\mathrm{HCl}$ in absence and presence of various concentrations of L- tryptophan and of Ltryptophan-surfactant mixtures at $30{ }^{\circ} \mathrm{C}$.

\begin{tabular}{lcccccc}
\hline \multicolumn{1}{c}{ Inhibitor conc. $(\mathrm{ppm})$} & $\mathrm{E}_{\text {corr }}(\mathrm{mV})$ & $\mathrm{I}_{\text {corr }}(\mu \mathrm{A})$ & $\beta_{\mathrm{c}}(\mathrm{mV})$ & $\beta_{\mathrm{a}}(\mathrm{mV})$ & $\mathrm{C} . \mathrm{R}(\mathrm{mpy})$ & $\% \mathrm{IE}$ \\
\hline Blank & -622.96 & 666.1 & 283.19 & 134.63 & 58.59 & - \\
L-trypt 100 & -614.41 & 466.8 & 263.92 & 116.64 & 42.76 & 29.920 \\
L-trypt 200 & -603.23 & 435.6 & 271.522 & 117.146 & 39.90 & 34.60 \\
L-trypt 500 & -573.99 & 170.1 & 181.23 & 121.33 & 15.59 & 74.46 \\
SDS 1 + L-trypt 100 & -591.88 & 349.6 & 255.07 & 111.37 & 32.02 & 47.51 \\
SDS 1 + L-trypt 200 & -582.88 & 307.1 & 243.11 & 106.35 & 28.13 & 53.89 \\
SDS 1 + L-trypt 400 & -579.26 & 204.4 & 216.94 & 85.54 & 18.72 & 69.31 \\
SDS 1 + L-trypt 500 & -569.54 & 109.9 & 206.43 & 55.75 & 10.06 & 83.50 \\
CTAB1 + L-trypt100 & -589.66 & 438.0 & 292.43 & 127.53 & 40.12 & 34.24 \\
CTAB1 + L-trypt200 & -581.45 & 327.7 & 264.54 & 120.69 & 30.02 & 50.80 \\
CTAB1+ L-trypt 400 & -565.617 & 171.0 & 286.99 & 99.09 & 15.66 & 74.328 \\
CTAB1+ L-trypt 500 & -567.777 & 130.5 & 285.87 & 94.42 & 11.95 & 80.408 \\
\hline
\end{tabular}

A plot of $\log \theta / 1-\theta$ vs.1/T, where $T$ is the solution temperature, was also obtained for L-tryptophan and for L-tryptophan in combination with $1 \mathrm{ppm}$ of surfactants (Fig. 2). The heat of adsorption $\left(\mathrm{Q}_{\mathrm{d}}\right)$ was calculated from the slope of the plot $\left(-\mathrm{Q}_{\mathrm{d}} / 2.303 \mathrm{R}\right)$ and the values are listed in Table 4 . The plot of $\log (\mathrm{CR} / \mathrm{T})$ vs. $1 / \mathrm{T}$ in presence of L-tryptophan and surfactants (Fig. 3) gave a straight line with slope of $(-\Delta \mathrm{H} / 2.303 \mathrm{R})$ and an intercept of $[(\log (\mathrm{R} / \mathrm{Nh})+(\Delta \mathrm{S} / 2.303 \mathrm{R})]$. The values of $\Delta \mathrm{H}$ obtained from the slope and of $\Delta \mathrm{S}$ evaluated from the intercept, are 
given in Table 4 . The values of free energy of adsorption $\left(\Delta \mathrm{G}_{\mathrm{ads}}\right)$ were calculated using the following equation [24] and are listed in Table 5.

$$
\Delta \mathrm{G}_{\mathrm{ads}}=-\mathrm{RT} \ln (55.5 \mathrm{~K})
$$

where $\mathrm{K}$ is equilibrium constants and is given by

$$
K=\frac{\theta}{C(1-\theta)}
$$

where $\theta$ is the degree of surface coverage, $\mathrm{C}$ the concentration of the inhibitors in mol dm$~^{-3}, \mathrm{R}$ is the gas constant and $\mathrm{T}$ is the solution temperature. The plots of log $\theta / 1-\theta$ vs. $\log C$ showed a linear correlation of slope close to unity, suggesting that the adsorption of L-tryptophan on mild steel surface obeys Langmuir adsorption isotherm. The values of heat of adsorption are less than - $40 \mathrm{KJ} \mathrm{mol}^{-1}$, suggesting the physical adsorption of the inhibitors [25]. The lower values of $\Delta \mathrm{H}$ for Ltryptophan in presence of surfactants indicate less energy barrier for the reaction [26]. The negative values of $\Delta \mathrm{G}_{\mathrm{ads}}$ suggest that the adsorption of L-tryptophan on mild steel is spontaneous. It is an established fact that values of $\Delta \mathrm{G}_{\text {ads }}$ around -20 $\mathrm{KJ} \mathrm{mol}^{-1}$ or less indicate physisorption. The adsorption is attributed to the electrostatic attraction between the charged organic molecules and charged metal surface. The values of $\Delta \mathrm{G}_{\mathrm{ads}}$ around - $40 \mathrm{KJ} \mathrm{mol}^{-1}$ or more are considered as chemisorptions. However, the values of $\Delta \mathrm{G}_{\mathrm{ads}}$ between -20 and $-40 \mathrm{KJ} \mathrm{mol}^{-1}$ give a disputed judgement about the type of adsorption [27-30]. In the present investigation the values of $\Delta \mathrm{G}_{\mathrm{ads}}$ are in the range of -26.70 to $-34.85 \mathrm{KJ} \mathrm{mol}^{-1}$, suggesting a mixed type of adsorption involving both physisorption and chemisorption.

\section{Potentiodynamic polarization measurements}

Potentiodynamic polarization curves for the corrosion of mild steel in $0.1 \mathrm{M} \mathrm{HCl}$ in absence and presence of different concentrations of L-tryptophan, and of Ltryptophan in combination with 1 ppm of SDS and CTAB, are shown in Fig. 4-6. The values of electrochemical parameters as deduced from these curves, e.g., corrosion potential $\left(E_{\text {corr }}\right)$, corrosion current density $\left(i_{\text {corr }}\right)$, cathodic Tafel slope (bc), anodic Tafel slope (ba) and \% inhibition efficiency (\% IE), are shown in Table 6. The IE was calculated using the equation:

$$
\% I E=\frac{i_{c o r r}^{o}-i_{\text {corr }}}{i_{\text {corr }}^{o}} \times 100
$$

where $i_{\text {corr }}^{\mathrm{o}}$ and $i_{\text {corr }}$ are the corrosion current density in absence and presence of the inhibitors, respectively. The study of electrochemical data reveals that the value of $i_{\text {corr }}$ continuously decreases in presence of L-tryptophan. The maximum IE of about $75 \%$ was observed at a concentration of $500 \mathrm{ppm}$, indicating that a higher coverage of L-tryptophan on steel surface is obtained in the solution with highest concentration of the inhibitor. The values of $E_{\text {corr }}$ shift to more positive value compared to the blank, indicating that L-tryptophan acts more as an anodic than a cathodic inhibitor. The addition of $1 \mathrm{ppm}$ of SDS and CTAB to different concentrations of L-tryptophan improved the IE of L-tryptophan significantly. 
The results as obtained by electrochemical studies are consistent with the results of the weight loss measurements.

\section{Conclusions}

(1) L-tryptophan showed good performance as corrosion inhibitor for mild steel in $0.1 \mathrm{M} \mathrm{HCl}$, which is further improved in presence of the surfactants SDS and CTAB. The effect of surfactants on corrosion inhibition behavior of L-tryptophan appears to be synergistic in nature.

(2) The data obtained from weight loss measurements suggest corrosion inhibition by adsorption mechanism and fit well the Langmuir adsorption isotherm. The thermodynamic data suggest mixed type of adsorption involving both physisorption and chemisorption.

(3) L-tryptophan acts more as an anodic than a cathodic inhibitor.

\section{References}

1. M. Lagrenee, B. Mernari, M. Bouanis, M. Traisrnel, F. Bentiss, Corros. Sci. 44 (2002) 573.

2. $\quad$ M.A. Quraishi, R. Sardar, Corrosion 58 (2002) 748.

3. M.A. Quraishi, S. Khan, J. Appl. Electrochem. 33 (2003) 233.

4. $\quad$ S. Bilgic, Korozyon 13 (2005) 3.

5. A.B. Silva, S.M.L. Agostinho, O.E. Barcia, G.G.O. Cordeiro, E. D'Elia, Corros. Sci. 48 (2006) 3668.

6. L. Toufari, A. Kadri, A. Khalifa, N. Aimeeur, N. Benbrahim, J. Eng. Appl. Sci. 3 (a) (2008) 688.

7. E.E. Oguzie, Y. Li, F.H. Wang, J. Electrochim. Acta 53 (2007) 909.

8. S.A. Umoren, I.B. Obot, N.O. Obi-Egbedi, J. Mater. Sci. 44 (2009) 274.

9. M.S. Morad, J. Appl. Electrochem. 38 (2008) 1509.

10. H. Ashassi-Sorkhabi, M.R. Majidi, K. Seyyedi, Appl. Surf. Sci. 225 (2004) 176.

11. V. Hluchan, B.L. Wheeler, N. Hackerman, Werkst. Korros. 39 (1988) 512.

12. G. Moretti, F. Guidi, Corros. Sci. 44(9) (2002) 1995.

13. J.J. Fu, S.N. Li, L.H. Cao, Y. Wang, L.H. Yan, L.D. Lu, J. Mater. Sci. 45 (2010) 979.

14. S.A. Umoren, U.M. Uduok, E.E. Oguzie, Port. Electrochim. Acta 26(6) (2008) 553.

15. M.Z.A. Rafiquee, N. Saxena, S. Khan, M.A. Quraishi, Mater. Chem. Phys. 107 (2008) 528.

16. M.A. Migahed, A.M. Al-Sabagh, Chem. Eng. Comm. 196 (2009) 1054.

17. M.L. Free, Corrosion 1025 (2002) 58.

18. W.L. Wang, M.L. Free, Corros. Sci. 2601 (2004) 46.

19. M. Saleh, A.A. Atha, J. Appl. Electrochem. 36 (2006) 899. 
20. H. Ashassi-Sorkhabi, Z. Ghasimi, D. Seifzadeh, Appl. Surf. Sci. 249 (2005) 408.

21. V.S. Rao, L.K. Singhal, J. Mater. Sci. 49 (2009) 2327.

22. O. Olivares-Xometl, N.V. Likhanova, R. Martinez-Palou, M.A. Dominguez-Aguilar, Mater. Corros. 60 (2009) 14.

23. K. Babic-Samardzija, C. Lupu, N. Hackerman, A.R. Barron, A. Luttge, Langmuir 21 (2005) 12187.

24. J.M. Cases, F. Villieras, Langmuir 8 (1992) 1251

25. L.J. Jha, Ph.D. Thesis, Faculty of Science, Delhi University, Delhi (1990).

26. S.A.R. Sayed, H.H. Hamdy, A.A. Mohammed, Mater. Chem. Phys. 70 (2001) 64.

27. F.S. de Souza, A. Spinelli, Corros. Sci. 51 (2009) 642.

28. W.H. Li, Q. He, S.T. Zhang, C.L.S. Pei, B.R. Hou, J. Appl. Electrochem. 38(3) (2008) 289.

29. G. Avci, Mater. Chem. Phys. 112 (2008) 234.

30. G.W. Castellan, Physical Chemistry, 2nd edn., Addison-Wesley, Reading MA (1984). 